\title{
Psychiatric Sequelae of Low Birth Weight at 6 Years of Age
}

\author{
Naomi Breslau, ${ }^{1,5,8,9}$ Gregory G. Brown, ${ }^{1,3}$ Jerel E. DelDotto, ${ }^{1,3}$ \\ Savitri Kumar, ${ }^{2,6}$ Sudhakar Ezhuthachan, ${ }^{2}$ Patricia Andreski, ${ }^{1}$ \\ and Karen G. Hufnagle ${ }^{4,7}$
}

The study examined the association between low birth weight $(\mathrm{LBW})(\leq 2,500$ g) and attention deficit hyperactivity disorder (ADHD) in two socioeconomically disparate populations. $L B W$ and normal birth weight (NBW) children from the 1983 to 1985 newborn lists of an urban and a suburban hospital in Southeast Michigan were randomly selected. A total of 823 children, $473 \mathrm{LBW}$ and $350 \mathrm{NBW}$, participated. Data were gathered in 1990 to 1992, when the children were 6 to 7 years of age. The National Institute of Mental Health Diagnostic Interview Schedule for children-Parent version (DISC-P) was used to elicit information on DSM-III-R diagnoses of simple phobia, overanxious, separation anxiety, oppositional defiant, and ADHD. Teachers' ratings of behavior problems were obtained. $L B W$ was associated with $A D H D$ but not with childhood anxiety disorders or oppositional defiant disorder. The association was stronger in the urban than in the suburban population. Data

Manuscript received in final form May 19, 1995.

This research was supported by NIMH research grant MH-44586 and NIMH Research Scientist Development Award MH-00380 to Dr. Breslau.

${ }^{1}$ Henry Ford Health Sciences Center, Department of Psychiatry, Detroit, Michigan 48202.

${ }^{2}$ Henry Ford Health Sciences Center, Department of Pediatrics, Division of Neonatology, Detroit, Michigan 48202.

${ }^{3}$ Henry Ford Health Sciences Center, Department of Psychiatry, Division of Neuropsychology, Detroit, Michigan 42202.

${ }^{4}$ William Beaumont Hospital, Neonatal Follow-Up, Troy, Michigan.

${ }^{5}$ University of Michigan School of Medicine, Ann Arbor, Michigan.

${ }^{6}$ University of Michigan, Department of Pediatrics and Communicable Diseases, Ann Arbor, Michigan.

${ }^{7}$ Wayne State University School of Medicine, Department of Pediatrics, Detroit, Michigan.

${ }^{8}$ Case Western Reserve University School of Medicine, Cleveland, Ohio.

${ }^{9}$ Address all correspondence to Naomi Breslau, Ph.D., Henry Ford Hospital, Department of Psychiatry, 1 Ford Place, 3A, Detroit, Michigan 48202-3450. 
from teachers' ratings revealed an association between $L B W$ and attention problems. The prognostic significance of the observed psychopathology at 6 years of age requires follow-up assessment as the children mature.

Current interest in the neuropsychiatric sequelae of low birth weight (LBW) $(\leq 2,500 \mathrm{~g})$ has its origins in the historic research conducted by Pasamanick, Lilienfeld and their associates (Pasamanick \& Knobloch, 1961; Pasamanick \& Lilienfeld, 1955; Pasamanick, Rogers, \& Lilienfeld, 1956). In case-control studies, they identified a wide range of childhood disorders associated with complications of pregnancy and delivery. They proposed that complications of pregnancy and delivery produce a "continuum of reproductive casualty," which ranges from death and profound disability to speech defects, reading disorders, and behavior problems. Studies that focused on attention deficit disorder produced mixed results on the role of complications of pregnancy and delivery (Goodman \& Stevenson, 1989; Sprich-Buckminster, Biederman, Milberger, Faraone, \& Lehman, 1993; Werner, Bierman, \& French, 1977). A recent case-control study reported that perinatal complications increased the risk for attention deficit disorder in children with comorbid disorders and with no family history of attention deficit disorder (Sprich-Buckminster et al., 1993).

LBW is correlated with prenatal problems, intrapartum complications, and neonatal disease and serves as a marker for defining a class of newborns at high risk for developmental deficits. Recent research on the longterm sequelae of LBW has focused primarily on the extreme low-end of the birth weight distribution, that is, very low birth weight (VLBW) $(\leq 1,500$ g) or extremely low birth weight $(\leq 1,000 \mathrm{~g})$. Studies of school age VLBW children have revealed increased rates of behavioral and academic problems among those thought to have passed their infancy intact (Hack et al., 1992; Hack et al., 1991; McCormick, Brooks-Gunn, Workman-Daniels, Turner, \& Peckham, 1992; McCormick, Gortmaker, \& Sobol, 1991; Saigal, Szatmari, Rosenbaum, Campbell, \& King, 1991; Szatmari, Saigal, Rosenbaum, Campbell, \& King, 1990; Teplin, Burchinal, Johnson-Martin, Humphrey, \& Kraybill, 1991; The Scottish Low Birthweight Study Group, 1992). There is evidence for a distinct pattern of behavior problems, namely, highactivity-level and low-attention-span, problems that are the cardinal features of attention deficit hyperactivity disorder (ADHD) (Buka, Lipsitt, \& Tsuang, 1991; Dunn et al., 1986; Hack et al., 1992; McCormick et al., 1990; The Scottish Low Birthweight Study Group, 1992). An increased risk for ADHD, defined according to Diagnostic and Statistical Manual of Mental Disorders (3rd ed., rev.) (DSM-III-R; American Psychiatric Association, 1987) criteria, was reported in 5 year-old children born $\leq 1,000 \mathrm{~g}$ (Szatmari 
et al., 1990). The few studies that examined behavior problems in a wider range of the LBW distribution suggest that the increased risk for behavior problems might not be confined to the VLBW range (Dunn et al., 1986; McCormick et al., 1992; Peterson, Greisen, Kovacs, Munck, \& Friis-Hansen, 1990; The Scottish Low Birthweight Study Group, 1992). There are, however, no reports on psychiatric disorders, as distinct from behavior problems, in LBW children born $>1,000 \mathrm{~g}$.

It has been suggested that social class might modify the impact of LBW on children's development (Escalona, 1982; Sameroff \& Chandler, 1975; Werner \& Smith, 1982). Accordingly, favorable environments in middleclass families might protect against the adverse effects of biologic vulnerability. Several studies reported differential LBW effects across social classes, whereas other studies found no support for the hypothesis that the social environment modifies the risks associated with LBW (Hack et al., 1992; McCormick et al., 1992; McGauhey, Starfield, Alexander, \& Ensminger, 1991; Teplin et al., 1991). An interaction between social class and VLBW $(\leq 1,500 \mathrm{~g})$ was reported recently for hyperactivity and motor-visual coordination, but not for IQ and other neurocognitive measures (LevyShiff, Einat, Mogilner, Lerman, \& Krikler, 1994).

We recently reported on the relationship between LBW and IQ at 6 years of age, based on a large-scale study of the entire LBW range $(\leq 2,500$ g) in an urban predominantly disadvantaged population and a suburban middle-class population (Breslau et al., 1994). Briefly, LBW was associated with lower IQ. There was no evidence of an interaction with population site, and the same IQ deficit was detected in both the urban and suburban populations.

In this report, we focus on common early childhood psychiatric disorders. We hypothesized an increased risk for ADHD in LBW children. Additionally, we tested the hypothesis that LBW might interact with the social environment, exerting a greater effect on ADHD in a disadvantaged urban population than in a middle-class suburban population.

\section{METHODS}

\section{Sample}

The sample was selected from the 1983 to 1985 lists of newborn discharges of two major hospitals in southeast Michigan, one in the city of Detroit (urban) and the other in a nearby middle-class suburb (suburban). The total number of newborn discharges for 1983 to 1985 in the urban hospital was 6,698 , of whom $739(11 \%)$ were LBW, i.e., $\leq 2,500 \mathrm{~g}$ at birth. 
During the same period, the total number of newborn discharges in the suburban hospital was 16,136 , of whom $1,031(6.4 \%)$ were LBW. In each hospital for each year from 1983 to 1985 , random samples of $140 \mathrm{LBW}$ $(\leq 2,500 \mathrm{~g})$ and 93 normal birth weight (NBW) $(>2,500 \mathrm{~g})$ newborns were drawn. The sampling scheme was designed to yield a ratio of 1.5:1 LBW to NBW children. The sample was decreased due to death, fostering of children, or families moving out of the metropolitan area. Children with severe neurologic impairment, ascertained at time of recruitment, were excluded, as our interest was in identifying the long-term sequelae of LBW among children who are considered to have escaped severe disability. The target sample comprised $618 \mathrm{LBW}$ and 477 NBW children.

Children were evaluated in 1990 to 1992, as they passed their sixth birthday. Families were invited to bring their selected child for 3 to 4 hours of evaluation. The participation rate was $75 \%$ and varied little by population site or birth weight status. Nonparticipants were similar to participants on racial composition, low-birth-weight status, and urban-suburban breakdown. The sample comprised 823 children, 473 LBW and 350 NBW, with approximately equal numbers of LBW and NBW in the urban and suburban subsets.

\section{Measurement}

The National Institute of Mental Health (NIMH) Diagnostic Interview Schedule for Children-Parent version 2.1 (DISC-P); (Shaffer et al., 1988) was used to elicit information from mothers on five DSM-III-R (APA, 1987) childhood psychiatric disorders: separation anxiety disorder, simple phobia, overanxious disorder, ADHD, and oppositional defiant disorder (ODD). A composite category, any anxiety disorder, combined simple phobia, separation anxiety, and overanxious disorder. The DISC is a fully structured interview, with a limited set of precoded replies, that inquires about criterial symptoms, as well as duration, frequency, impairment, and other modifiers used in the DSM-III-R diagnostic definitions (Costello, Edelbrock, Dulcan, Kalas, \& Klaric, 1984). (Methodologic papers on the DISC 2.1 were published in the May 1993 issue of the Journal of the American Academy of Child and Adolescent Psychiatry.) Because of the young age of the children, psychiatric assessment relied exclusively on information elicited from mothers and did not include direct interviews with the children. A recent study reported high reliability of the DISC-P for diagnosing ADHD (Schwab-Stone, Fallon, Briggs, \& Crowther, 1994). Trained lay-interviewers conducted face-to-face interviews with mothers. Interviewers were blind to the LBW status of the child. 
Data on behavior problems were obtained from teachers' ratings on the Teacher's Report Form (TRF; Achenbach, 1991). The TRF contains eight behavior problems scales, derived by factor analysis. They are Withdrawn, Somatic Complaints, Anxious/Depressed, Social Problems, Attention Problems, Delinquent Behavior, and Aggressive Behavior. The Attention Problems scale has 20 items, among them the cardinal symptoms of ADHD (e.g., fails to finish things he/she starts; can't concentrate, pay attention for long; can't sit still; fidgets; daydreams or gets lost in his/her thoughts; difficulty following directions; impulsive or acts without thinking; messy work; inattentive, easily distracted; fails to carry out assigned tasks.) Teachers were not informed about the LBW status of the child.

ADHD was measured in two ways. The first was based exclusively on parents' information elicited by the DISC-P. The second method combined parents' DISC data with teachers' ratings on the Attention Problems scale of the TRF. The combined measure required a DISC-P diagnosis of $\mathrm{ADHD}$ and teacher's rating exceeding 1.5 standard deviations above the mean.

Information on birth weight and other perinatal variables, including gestational age, Apgar score, and number of days in neonatal intensive care unit, was abstracted from medical records. The children's assessment at 6 years of age employed a comprehensive neuropsychologic battery that included the Wechsler Intelligence Scale for Children-Revised (WISC-R; Wechsler, 1974) and tests of key cognitive domains. Experienced neuropsychology technicians, trained and supervised by a child neuropsychologist, conducted individual assessments according to a standardized protocol. All assessments were conducted blindly.

Maternal IQ was measured by the Two-Subtest Short Form of the Wechsler Adult Intelligence Scale-Revised (WAIS-R; Silverstein, 1982). Maternal history of psychoactive substance abuse/dependence was measured by the NIMH Diagnostic Interview Schedule, revised according to DSM-III-R (Robins, Helzer, Cottler, \& Golding, 1989).

\section{Statistical Analysis}

The relationship of LBW with ADHD was estimated by relative risks (RRs) as well as by crude and adjusted odds ratios (ORs). The BreslowDay test (Breslow \& Day, 1980) for departure from homogeneity of the odds ratios was used to test for interactions between LBW and social disadvantage. Multiple logistic regression was used to estimate adjusted odds ratios, controlling for covariates. 
Table I. Demographic and Perinatal Characteristics ${ }^{a}$

\begin{tabular}{|c|c|c|c|c|}
\hline & \multicolumn{2}{|c|}{ Urban } & \multicolumn{2}{|c|}{ Suburban } \\
\hline & $\begin{array}{c}\text { LBW } \\
(n=238)\end{array}$ & $\begin{array}{c}\text { NBW } \\
(n=176)\end{array}$ & $\begin{array}{c}\text { LBW } \\
(n=235)\end{array}$ & $\begin{array}{c}\text { NBW } \\
(n=174)\end{array}$ \\
\hline$\%$ Black & 80 & 74 & 11 & 3 \\
\hline$\%$ Males & 42 & 48 & 52 & 54 \\
\hline \multicolumn{5}{|l|}{ Mothers' education } \\
\hline$\%<\mathrm{HS}$ & 30 & 22 & 7 & 8 \\
\hline$\%$ HS & 24 & 26 & 30 & 30 \\
\hline$\%$ Part college & 37 & 39 & 39 & 24 \\
\hline$\%$ College & 10 & 14 & 23 & 28 \\
\hline$\%$ Single mothers & 38 & 33 & 14 & 9 \\
\hline \multicolumn{5}{|l|}{ Apgar } \\
\hline$\% 1 \min \leq 5$ & 16 & 6 & 22 & 4 \\
\hline$\% 5 \min \leq 5$ & 2 & 1 & 3 & 0 \\
\hline \multicolumn{5}{|l|}{ NICU days } \\
\hline$\% 0$ & 58 & 94 & 54 & 99 \\
\hline$\% 1$ to 9 & 8 & 6 & 3 & 0 \\
\hline$\% 10$ to 19 & 12 & 0 & 10 & 1 \\
\hline$\% \geq 20$ & 22 & 0 & 33 & 0 \\
\hline \multicolumn{5}{|l|}{ Birth weight } \\
\hline$\%<1,500 \mathrm{~g}$ & 14.7 & & 17.4 & \\
\hline$\% 1,501$ to 2,000 & 21.4 & & 17.9 & \\
\hline$\% 2,001$ to 2,500 & 63.9 & & 64.7 & \\
\hline \multicolumn{5}{|l|}{ Maternal Hx } \\
\hline$\%$ Substance A/D & 14 & 11 & 16 & 10 \\
\hline \% Smoking & 44 & 22 & 35 & 17 \\
\hline
\end{tabular}

${ }^{a}$ LBW $=$ low birth weight; NBW = normal birth weight; HS = high school; NICU = neonatal intensive care unit; $\mathrm{HX}=$ history; $\mathrm{A} / \mathrm{D}$ abuse/dependence. Substance $\mathrm{A} / \mathrm{D}$ includes alcohol and illicit drug abuse or dependence. Smoking refers to history of smoking 2 months or more during pregnancy.

\section{RESULTS}

\section{Comparison of the Urban and Suburban Samples}

The urban and suburban samples differed markedly in racial composition, maternal education, and single-parent status, while differences between the LBW and NBW subsets within each site were small (Table I). The urban sample was predominantly black; approximately $25 \%$ of the mothers had not completed high school and more than one-third were single. In contrast, the suburban sample was nearly all white; only $7 \%$ of the mothers had failed to complete high school and approximately $10 \%$ were 
single. Approximately $50 \%$ of urban mothers and more than $60 \%$ of suburban mothers were employed. The proportions of Hispanics and other minorities in the populations sampled were extremely small, reflecting the ethnic composition of the Detroit metropolitan area. The LBW and NBW subsets in the urban population were similar to their suburban counterparts with respect to the proportions with low Apgar scores, use of neonatal intensive care unit (NICU), maternal history of substance abuse/dependence, and smoking during pregnancy (Table I).

\section{DISC-P Psychiatric Disorders Associated with LBW}

The rates of five DSM-III-R disorders in LBW and NBW children in the urban and suburban sites appear in Table II. Relative risks (RRs) and $95 \%$ confidence intervals (CI) associated with $\mathrm{LBW}$ are presented as well. Consistent with our hypothesis, the rate of ADHD was higher in LBW than NBW children. Additionally, the association of LBW with ADHD was stronger in the urban than suburban site. The rate of ADHD in urban LBW children was markedly higher than in urban NBW children, $31.9 \%$ versus $15.9 \%, \mathrm{RR}=2.0(95 \%$ CI 1.4 to 2.9$)$; in the sub urban site the rates in LBW and NBW children were $14.5 \%$ versus $13.2 \%$, $\mathrm{RR}=1.1(95 \% \mathrm{CI} 0.7$ to 1.8$)$. The odds ratio for the urban site was 2.5 (95\% CI 1.5 to 4.0 ) and for the suburban site 1.1 (95\% CI 0.6 to 2.0 ) The Breslow-Day test for departure from homogeneity of the estimates was statistically significant $\left(\chi^{2}=4.5,1 d f, p=.035\right)$, indicating that the effect of LBW on ADHD varied between the two populations. The adjusted odds ratio for ADHD associated with LBW in the urban site was 2.4 (95\% CI 1.4 to 3.9 ) and in the suburban site 1.0 (95\% CI 0.6 to 1.8 ), estimated in site-specific logistic regressions, controlling for sex, race, maternal education, and maternal IQ. The adjusted odds ratios varied little from the crude odds ratios. On any anxiety disorder and oppositional defiant disorder, differences between LBW and NBW children were not significant.

We evaluated the extent to which the observed relationship of LBW with ADHD was accounted for by perinatal risk factors, including singlemother status, maternal history of substance abuse/dependence, and smoking during pregnancy. Bivariate analysis suggested weak associations between $\mathrm{ADHD}$ and maternal history of substance abuse/dependence as well as smoking in pregnancy. However, when added into the multivariate model, these variables did not have significant associations with ADHD and did not alter the findings summarized above. 


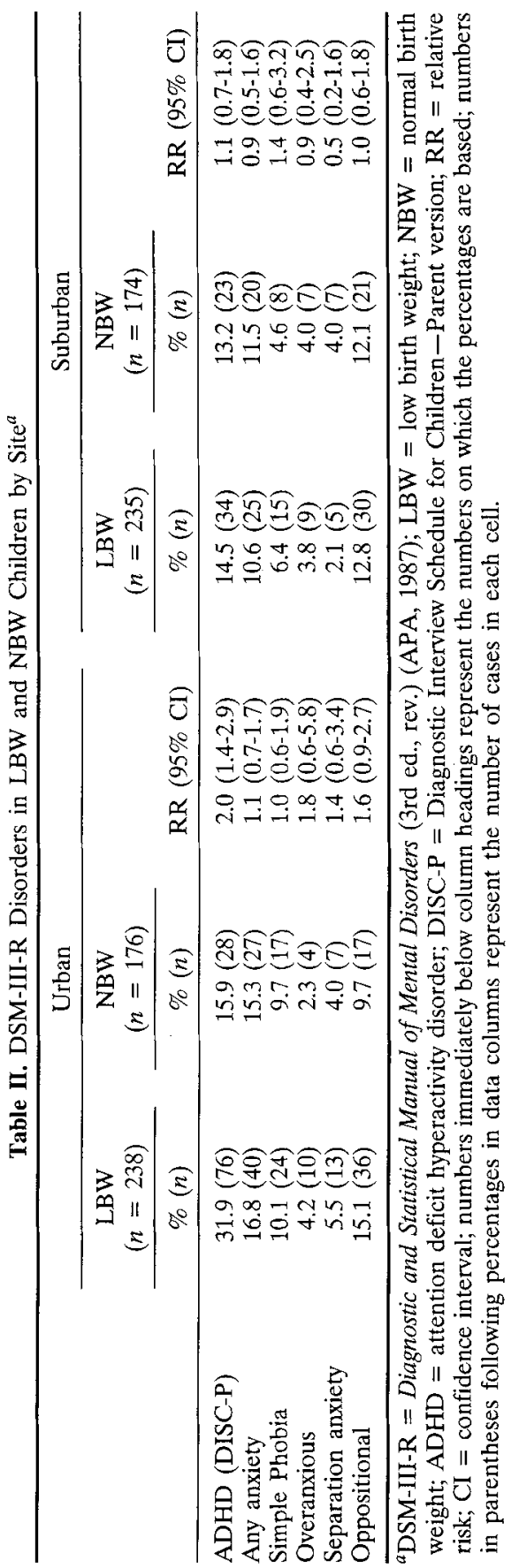


Table III. Patterns of Comorbidity with ADHD in LBW and NBW Children ${ }^{a}$

\begin{tabular}{lcccccc}
\hline & \multicolumn{2}{c}{$\begin{array}{c}\text { LBW } \\
(n=110)\end{array}$} & & \multicolumn{3}{c}{$\begin{array}{c}\text { NBW } \\
(n=51)\end{array}$} \\
\cline { 2 - 3 } \cline { 5 - 7 } & $\%$ & $(n)$ & & $\%$ & $(n)$ \\
\hline "Pure" ADHD & 46.4 & $(51)$ & & 45.1 & $(23)$ \\
ADHD + ODD & 39.0 & $(43)$ & & 39.2 & $(20)$ \\
ADHD + Anxiety disorders & 14.6 & $(16)$ & & 15.7 & $(8)$ \\
\hline
\end{tabular}

$\overline{{ }^{a} \mathrm{ADHD}}=$ attention deficit hyperactivity disorder; LBW $=$ low birth weight; NBW $=$ normal birth weight; ODD = oppositional-defiant disorder.

\section{Patterns of Comorbidity with ADHD}

We explored the relationship between LBW and ADHD, classified according to the presence or absence of comorbidity (Table III). The majority of LBW as well as NBW children with ADHD - more than 50\% - met criteria for another psychiatric disorder. Oppositional defiant disorder was the most common comorbid disorder in both LBW and NBW children with ADHD, with more than $70 \%$ of the comorbid ADHD cases in each group meeting criteria for ODD. The association between LBW and ADHD did not vary by type of ADHD, according to these results.

\section{$L B W-A D H D$ Association by Level of IQ}

An exploratory analysis, presented in Table IV, suggested that the relationship between LBW and ADHD varied by level of IQ. LBW children with IQ $<80$ showed the highest rate of ADHD and those with IQ 80 to 99 an intermediate rate. LBW children with IQ $\geq 100$ were not more likely than NBW children to be diagnosed with ADHD.

\section{Teachers' Ratings of Attention Problems}

Teachers' ratings of child behavior problems, measured by the Teacher's Report Form were used as a separate source of information for testing the LBW-ADHD relationship. A series of two-way analyses of variance (ANOVAs) were performed on the eight behavior problems, with LBW and population site as independent variables. Because interactions between LBW and population site were found not to be significant on any scale $(p>.10)$ the analyses were performed on the combined urban and suburban population. 
Table IV. ADHD in LBW Children by Level of IQ $^{a}$

\begin{tabular}{|c|c|c|c|c|}
\hline & \multirow[b]{2}{*}{$(n)$} & \multicolumn{2}{|c|}{ ADHD } & \multirow[b]{2}{*}{$\mathrm{RR}(95 \% \mathrm{CI})$} \\
\hline & & $\%$ & $(n)$ & \\
\hline LBW, IQ <80 & $(54)$ & 53.7 & (29) & $3.7(2.6-5.2)$ \\
\hline LBW, IQ 80-99 & (168) & 29.2 & (49) & $2.0(1.4-2.8)$ \\
\hline LBW, IQ $\geq 100$ & (251) & 12.8 & (32) & $0.9(0.6-1.3)$ \\
\hline NBW & (350) & 14.6 & $(51)$ & Reference \\
\hline
\end{tabular}

${ }^{a} \mathrm{ADHD}=$ attention deficit hyperactivity disorder; LBW $=$ low birth weight; IQ $=$ intelligence quotient; $\mathrm{RR}=$ relative risk; $\mathrm{CI}=$ confidence interval; $\mathrm{NBW}=$ normal birth weight. Numbers in second column represent the numbers on which the percentages are based; numbers in parentheses below ADHD column head represent the numbers of ADHD cases in cells.

Table $\mathrm{V}$ presents least-squares means and standard errors of behavior problem scores for LBW and NBW children, calculated in multiple-regression analyses, controlling for population site, sex, race, and maternal education. Statistical significance tests for the differences in the adjusted means of LBW versus NBW are included in the table. Using an alpha level corrected for multiple comparisons $(0.5 / 8=.006)$, a significant LBW effect was observed on the Attention Problems scale, consistent with the hypothesis of an LBW-ADHD association. A significant association was found also with the Withdrawn Symptoms scale, the only exception to the specificity of the LBW-ADHD relationship.

Although interactions between LBW and population site were not significant, LBW effects on the Attention Problems scale was greater in the urban than the suburban site. Specifically, the adjusted excess in Attention

Table V. Adjusted Means (Standard Errors) of Eight TRF Behavior Problems Scales in LBW and NBW Children $(n=801)^{a}$

\begin{tabular}{lcccc}
\hline & LBW & NBW & & \\
& Mean (SE) & Mean (SE) & $t$ & $p$ \\
\hline Withdrawn & $2.22(.13)$ & $1.61(.15)$ & 3.00 & .003 \\
Somatic complaints & $0.55(.06)$ & $0.47(.07)$ & 0.83 & .404 \\
Anxious/Depressed & $3.24(.18)$ & $2.68(.21)$ & 2.01 & .044 \\
Social Problems & $2.09(.12)$ & $1.62(.14)$ & 2.45 & .014 \\
Thought Problems & $0.30(.04)$ & $0.28(.04)$ & 0.27 & .788 \\
Attention Problems & $9.65(.40)$ & $6.84(.47)$ & 4.50 & .0001 \\
Delinquent Behavior & $1.24(.09)$ & $0.88(.10)$ & 2.67 & .008 \\
Aggressive Behavior & $5.76(.36)$ & $4.63(.42)$ & 2.02 & .044 \\
\hline
\end{tabular}

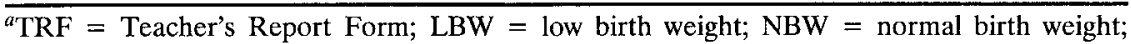
$\mathrm{SE}=$ standard error. Least-square means (SE) calculated in multiple regressions with population site, sex, race, maternal education and IQ, as covariates. 
Problems in LBW versus NBW urban children was nearly double the excess in LBW versus NBW suburban children -3.80 versus 1.98 , respectively.

Teachers' ratings on the Attention Problems scale were used also to compare LBW and NBW children on the percentages scoring above the normal range, using the cutoffs proposed by Achenbach (1991). Applying cutoff points that identify children in the borderline and clinical range, LBW effects on attention problems were stronger in the urban than in the suburban population. In the urban population, $16.1 \%$ LBW versus $5.8 \%$ NBW scored in the borderline or clinical range $\left(\chi^{2}=9.9,1 d f, p=.002\right)$, whereas in the suburban population, the corresponding proportions were $7.4 \%$ versus $5.3 \%\left(\chi^{2}=0.7,1 d f, p=.415\right)$. The results based on the teachers' ratings replicated those based on parents' DISC-P information in showing that LBW was associated with ADHD and that the association was stronger in the urban than the suburban population.

\section{Combining Parents' and Teachers' Data}

ADHD was measured also by combining DISC-P data and teachers' ratings on the Attention Problems scale. The combined diagnosis of ADHD required both a DISC-P diagnosis and a teacher's rating of Attention Problems higher than 1.5 standard deviations above the mean. The requirement that the DISC-P diagnosis be supported by a teacher's rating of Attention Problems above the 1.5 standard deviation cutoff reduced the overall number of children with ADHD from 161 to 60 . The rates of LBW and NBW urban children meeting the combined criteria were $13.9 \%$ versus $4.1 \%$, RR $=3.4(95 \% \mathrm{CI} 1.5$ to 7.5$)$. The corresponding rates in suburban LBW and NBW children were $6.9 \%$ versus $3.0 \%, \mathrm{RR}=2.3(95 \% \mathrm{CI} 0.9$ to 6.8$)$. The odds ratio for the urban comparison was 3.8 (95\% CI 1.6 to 8.8 ) and for the suburban comparison 2.4 (95\% CI 0.9 to 6.3). The Breslow-Day test of departure from homogeneity of the odds ratio was $0.4(1 d f), p=.52$, indicating no evidence of an interaction between LBW and site with respect to ADHD.

\section{DISCUSSION}

The results of this study on 6-year-old LBW children corroborate recent studies on very-low-birth-weight children, which have reported an excess in inattention and hyperactivity problems at school age. The study extends these observations to all LBW children, up to 2,500 g, and suggests that the association applies to ADHD proper. In contrast with ADHD, we 
found no association between LBW and other common early childhood disorders, namely, childhood anxiety disorders and oppositional defiant disorder. The association of LBW with ADHD was stronger in the urban population than in the suburban middle-class population. The hypothesis that LBW is associated with ADHD was supported in data from mothers' DISC-P interviews, teachers' ratings of attention problems, and data based on a combined algorithm that required both a DISC-P diagnosis and a teacher's rating of 1.5 standard deviations above the mean. Data based on the three approaches converge on the key findings, namely, that LBW was associated with ADHD and that the association might be stronger in the urban than the suburban site.

Additional analysis suggested that ADHD in LBW did not differ from ADHD in NBW children with respect to associated comorbidity. Approximately $50 \%$ of LBW as well as NBW children with ADHD met criteria for at least one additional disorder. We also found evidence to suggest that the association of LBW with ADHD varied by level of IQ and that LBW children with subnormal IQ $(<80)$ had the highest liability for ADHD.

Social class and membership in a racial minority are highly associated with biologic determinants of LBW, including maternal age, parity, birth interval, infection, tobacco and alcohol consumption, and poor nutrition (Kramer, 1987). They are associated also with other suspected risk factors for LBW, including stressful life events, maternal anxiety, and the absence of prenatal care. Some of these specific risk factors as well as social disadvantage in general, are also established risk factors for children's psychopathology. To guard against the confounding effects of social class and race, we compared LBW children to NBW counterparts in two socially disparate populations. Within each population, the demographic composition of LBW children was similar to that of NBW children. Controlling statistically for key indicators of social disadvantage reduced further the potential effects of remaining social differences between LBW and NBW. The effects of specific factors, such as maternal history of smoking and substance abuse, were ruled out in our analysis, once indicators of social class were controlled. Thus, by holding race and social class constant, we also controlled the effects of these specific factors, as well as a myriad of other factors that are highly associated with social disadvantage.

It should be noted that variables that can be characterized as causally intervening between LBW and children's psychopathology were not included in the list of potential confounders. Controlling for intermediate variables that may themselves have been affected by the risk factor (here LBW) can spuriously obscure any evidence in the data of a true causal association (Kleinbaum, Kupper, \& Morgenstern, 1982; Weinberg, 1993). Thus, parental overprotection, recurrent childhood illnesses, and other 
factors for which children might be at risk by virtue of their LBW status should not be treated as potential confounders.

The ADHD sequelae of LBW estimated in this study are conservative, as we did not include LBW children with severe neurologic handicaps, in whom psychopathology can be expected to be an aspect of their frank neurologic abnormality (Breslau, 1985, 1990).

The findings on the effects of LBW on DSM-III-R ADHD are based on data from mothers' reports on the NIMH DISC. A recent study of the reliability of the DISC for diagnosing psychiatric disorders in children 6 to 11 years of age has reported an excellent reliability of the Parent DISC for diagnosing ADHD (kappa = .81) (Schwab-Stone et al., 1994). The reliability of the Parent DISC for diagnosing other disorders of relevance to this study were in the good to fair range. Because the reliability of the Child DISC for diagnosing children 6 to 11 years of age was low across all disorders, the parent report remains the mainstay for diagnostic assessment of young children (Schwab-Stone et al., 1994). The rate of ADHD in all NBW children (urban and suburban), $14.5 \%$, is higher than the rates reported in some (but not all) epidemiologic studies. While the measurement approach might have been overinclusive, there is no reason to suspect that the relative prevalence of $\mathrm{ADHD}$ in $\mathrm{LBW}$ versus NBW was biased by a tendency of the method to overdiagnose. Combining both sources of data for diagnosing ADHD yielded lower rates of ADHD, but confirmed the association between LBW and ADHD.

Alternative explanations for the interaction between LBW and social disadvantage on ADHD might be suggested. First, suburban children might be protected from some of the adverse behavioral sequelae of LBW by the social-environmental advantages provided to children in middle-class communities. Second, the possibility that suburban mothers of LBW children might have underreported ADHD symptoms cannot be dismissed, although the plausibility of this explanation is diminished by corroborating evidence in teachers' data on attention problems. Third, because data on family history of ADHD were not available in this study, we could not examine whether LBW interacts with vulnerability to ADHD and the extent to which such a diathesis might have contributed to the stronger association between LBW and ADHD in the urban than the suburban population. The possibility that LBW might increase the liability for ADHD in children with familial vulnerability to the disorder deserves attention in future research.

ADHD in LBW children represents an aspect of the continuum of reproductive casualty, described by Pasamanick, Lilienfeld and their associates (Pasamanick \& Knobloch, 1961; Lilienfeld, 1955; Pasamanick et al., 1956). Brain injury as well as abnormal brain development prenatally and perinatally have been suggested as the mechanisms in subtle visual-motor 
and visual-perceptual deficits, as well as hyperactivity in preterm children (Ellis, Goetzman, \& Lindenberg, 1988; Fuller, Guthrie, \& Alvord, 1983; Grunnett, Curless, Bray, \& Jung, 1974; Leech \& Alvord, 1974; Marlow, Roberts, \& Cooke, 1989; Takashima, Becker, \& Chau, 1982; Trompeter, Dobbin, Aynsley-Green, \& Baum, 1976). The prognostic significance of these behavior problems for later functioning requires follow-up assessment as the children mature, including assessment of psychiatric and learning disorders and academic achievement.

\section{REFERENCES}

Achenbach, T. M. (1991). Teacher's Report Form. Burlington, VT: Center for Children, Youth and Families.

Achenbach, T. M., \& Edelbrock, C. (1991). Manual for the Child Behavior Checklist. Queen City Printers, Inc.

American Psychiatric Association (1987). Diagnostic and statistical manual of mental disorders (3rd ed., rev.). Washington, DC: Author.

Breslau, N. (1985). Psychiatric disorder in children with physical disabilities. Journal of the American Academy of Child Psychiatry, 24, 87-94.

Breslau, N. (1990). Does brain dysfunction increase children's vulnerability to environmental stress? Archives of General Psychiatry, 47, 15-20.

Breslau, N., DelDotto, J. E., Brown, G. C., Kumar, S., Ezhuthachan, S., Hufnagle, K. G., \& Peterson, E. L. (1994). A gradient relationship between low birth weight and IQ at 6 years. Archives of Pediatric and Adolescent Medicine, 148, 377-383.

Breslow, N. E., \& Day, N. E. (1980). Statistical methods in cancer research, Volume 1: The analysis of case-control studies. Lyon: International Agency for Research on Cancer.

Buka, S. L., Lipsitt, L. P., \& Tsuang, M. T. (1992). Emotional and behavioral development of low-birthweight infants. In S. L. Friedman \& M. D. Sigman (Eds.), The psychological development of low-birthweight children: Annual advances in applied developmental psychology (Vol. 6, pp. 187-214). Norwood, NY: Ablex.

Costello, A. J., Edelbrock, C., Dulcan, M. K., Kalas, R., \& Klaric, S. H. (1984). The National Institute of Mental Health Diagnostic Interview Schedule for Children (DISC): Final Report. Rockville, MD: National Institute of Mental Health.

Dunn, H. G., H. H. H., \& Schulzer, M. (1986). Minimal brain dysfunctions. In H. G. Dunn (Ed.), Sequelae of Low Birthweight: The Vancouver Study. Oxford, England. MacKeith Press.

Ellis, W. G., Goetzman, B. W., \& Lindenberg, J. A. (1988). Neuropathologic documentation of prenatal brain damage. American Journal of Diseases of Children, 142, 858-866.

Escalona, S. K. (1982). Babies at double hazard: Early development in infants at biologic and social risk. Pediatrics, 70, 670-676.

Fuller, P. W., Guthrie, R. D., Alvord, E. C. (1983). A proposed neuropathological basis for learning disabilities in children born prematurely. Developmental Medicine and Child Neurology, 25, 214-231.

Goodman, R., \& Stevenson, J. (1989). A twin study of hyperactivity II: The aetiological role of genes, family relationships and perinatal adversity. Journal of Child Psychology and Psychiatry, 30, 691-709.

Grunnet, M. L., Curless, R. G., Bray, P. F., \& Jung, A. L. (1974). Brain changes in newborns from an intensive care unit. Developmental Medicine and Child Neurology, 16, 320-328.

Hack, M., Breslau, N., Aram, D., Weissman, B., Klein, N., \& Borawski-Clark, E. (1992). The effect of very low birth weight and social risk on neurocognitive abilities at school age. Journal of Developmental and Behavioral Pediatrics, 13, 412-420. 
Hack, M., Breslau, N., Weissman, B., Aram, D., Klein, N., \& Borawski, E. (1991). Effect of very low birth weight and subnormal head size on cognitive abilities at school age. New England Journal of Medicine, 325, 231-237.

Kleinbaum, D. V., Kupper, L. L., Morgenstern, H. (1982). Epidemiologic research: Principles and quantitative methods. New York: Van Nostrand Reinhold.

Kramer, M. S. (1987). Determinants of low birthweight: Methodological assessment and metaanalysis. Bulletin of the World Health Organization, 65, 663-737.

Leech, R. W., \& Alvord, E. C., Jr. (1974). Perinatal leukoencephalopathy, an expanded concept. Journal of Neuropathology and Experimental Neurology, 33, 568-569.

Levy-Shiff, R., Einat, G., Mogilner, M. B., Lerman, M., \& Krikler, R. (1994). Biological and environmental correlates of developmental outcome of prematurely born infants in early adolescence. Journal of Pediatric Psychology, 19, 63-78.

Marlow, N., Roberts, B. L., \& Cooke, R. W. I. (1989). Motor skills in extremely low birthweight children at the age of 6 years. Archives of Disease in Childhood, 64, 839-847.

McCormick, M. C., Brooks-Gunn, J., Workman-Daniels, K., Turner, J., \& Peckham, G. J. (1992). The health and developmental status of very low-birth-weight children at school age. Journal of the American Medical Association, 267, 2204-2208.

McCormick, M. C., Gortmaker, S. L., \& Sobol, A. M. (1990). Very low birth weight children: Behavior problems and school difficulty in a national sample. Journal of Pediatrics, 117, 686-693.

McGauhey, P. J., Staffield, B. H., Alexander, C., \& Ensminger, M. E. (1991). Social environment and vulnerability of low birth weight children: A social-epidemiological perspective. Pediatrics, 88, 943-953.

Pasamanick, B., \& Knobloch, H. (1961). Epidemiologic studies on the complications of pregnancy and the birth process. In G. Caplan (Ed.), Prevention of Mental Disorders in Children (pp. 74-94). New York: Basic Books.

Pasamanick, B., \& Lilienfeld, A. M. (1955). Association of maternal and fetal factors with development of mental deficiency: Abnormalities in the prenatal and perinatal periods. Journal of the American Medical Association, 159, 155-160.

Pasamanick, B., Rogers, M. E., \& Lilienfeld, A. M. (1956). Pregnancy experience and the development of behavior disorder in children. American Journal of Psychiatry, 112, 613618.

Peterson, M. B., Greisen, G., Kovacs, R., Munck, H., \& Friis-Hansen, B. (1990). Status at four years of age in 280 children weighing $2,300 \mathrm{~g}$ or less at birth. Danish Medical Bulletin, 37, $546-552$.

Robins, L., Helzer, J., Cottler, L., \& Golding, E. (1989). The NIMH Diagnostic Interview Schedule, Version III, Revised. St. Louis, MO: Washington University.

Saigal, S., Szatmari, P., Rosenbaum, P., Campbell, D., \& King, S. (1991). Cognitive abilities and school performance of extremely low birth weight children and matched term control children at age 8 years: A regional study. Journal of Pediatrics, 118, 751-760.

Sameroff, A. J., \& Chandler, M. (1975). Reproductive risk and the continuum of caretaking casualty. In F. D. Horowitz, M. Hetherington, S. Scarr-Salapatek, \& G. Siegel (Eds.), Review of Child Development Research (Vol. 4). Chicago: University of Chicago Press.

Schwab-Stone, M., Fallon, T., Briggs, M., \& Crowther, B. (1994). Reliability of diagnostic reporting for children 6-11 years: A test-retest study of the revised Diagnostic Interview Schedule for Children. American Journal of Psychiatry, 151, 1048-1054.

Shaffer, D., Schwab-Stone, M., Fisher, P., Davies, M., Piacentini, J., \& Gioia, P. (1988). A revised version of the Diagnostic Interview Schedule for Children (DISC-R): Results of a field trial and proposals for a new instrument (DISC-2). Rockville, MD: Epidemiology and Psychopathology Research Branch, Division of Clinical Research, National Institute of Mental Health.

Silverstein, A. B. (1982), Two- and four-subtest short forms of the Wechsler Adult Intelligence Scale-Revised. Journal of Consulting and Clinical Psychology, 50, 425-418.

Sprich-Buckminster, S., Biederman, J., Milberger, S., Faraone, S. V., \& Lehman, B. K. (1993). Are perinatal complications relevant to the manifestation of ADD? Issues of comorbidity 
and familiality. Journal of the American Academy of Child and Adolescent Psychiatry, 32, $1032-1037$.

Szatmari, P., Saigal, S., Rosenbaum, P., Campbell, D., \& King, S. (1990). Psychiatric disorders at five years among children with birth weights $<1000 \mathrm{~g}$ : A regional perspective. Developmental Medicine and Child Neurology, 32, 954-962.

Takashima, S., Becker, L. E., Chan, F. (1982). Retardation of neuronal maturation in premature infants compared with term infants of the same post-conceptional age. Pediatrics, 69, 33-39.

Teplin, S. W., Burchinal, M., Johnson-Martin, N., Humphry, R. A., \& Kraybill, E. N. (1991). Neurodevelopmental, health, and growth status at age 6 years of children with birth weights less than 1001 grams. Journal of Pediatrics, 11, 768-777.

The Scottish Low Birthweight Study Group. (1992). The Scottish low birthweight study: II. Language attainment, cognitive status, and behavioral problems. Archives of Disease in Childhood, 67, 682-686.

Trompeter, R. S., Dobbing, J., Aynsley-Green, A., \& Baum, J. D. (1976). Neonatal brain growth during prolonged intravenous feeding. Archives of Disease in Childhood, 51, 316318.

Wechsler, D. (1974). Wechsler Intelligence Scale for Children-Revised. New York: Psychological Corporation.

Weinberg, C. R. (1993). Toward a clearer definition of confounding. American Journal of Epidemiology, 137, 1-8.

Werner, E. E., Bierman, J. M., \& French, F. E. (1971). The Children of Kauai: A longitudinal study from the prenatal period to age ten. Honolulu: University of Hawaii Press.

Werner, E. E., \& Smith, R. S. (1982). Vulnerable, but invincible: A longitudinal study of resilient children and youth. New York: McGraw-Hill. 